\title{
The Prescription of Anticraving Medication and its Economic Consequences
}

\author{
Rüdiger Holzbach ${ }^{a, b}$ Gunnar Stammen ${ }^{c}$ Ute Kirchhof ${ }^{d}$ Norbert Scherbaum ${ }^{e}$ \\ ${ }^{a}$ Klinik für Psychiatrie, Psychotherapie und Psychosomatik, Klinikum Arnsberg, Arnsberg, Germany; ${ }^{b}$ Centre of \\ Interdisciplinary Addiction Research (ZIS) of the University of Hamburg, Hamburg, Germany; ${ }^{\complement}$ Krankenhaus Maria

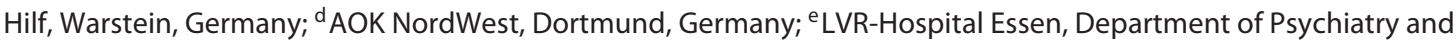 \\ Psychotherapy, Faculty of Medicine, University of Duisburg-Essen, Essen, Germany
}

\section{Keywords}

Anticraving medication · Empidemiology · Naltrexone ·

Acamprosate $\cdot$ Health economy

\begin{abstract}
Importance: According to recent studies, only a small proportion of alcoholics in the system for addiction treatment receive expedited treatment [Rehm et al.: Sucht 2014;60:93105 ] and that those who are untreated are at risk of harmful and dependent alcohol consumption. This is associated with significantly negative effects on morbidity, mortality, and quality of life [Kraus et al.: Sucht 2010;56:337-347]. As a result, not only individuals and their environment suffer but there is also a health economic impact. Objective: How often do patients with a primary or secondary diagnosis of alcohol dependence who have been discharged from inpatient treatment receive anticraving medication in the follow-up period of 6 months? Design, Setting, and Participants: Based on data from a statutory health insurance in Germany, 12,958 patients were investigated regarding alcohol dependence, rates for readmission to hospital, and prescription of anticraving drugs. In addition, outpatient and inpatient treatment costs were calculated. Main Outcomes and Measures: There will be an examination of how often anticraving medications are prescribed and what the economic conse-
\end{abstract}

\section{KARGER}

(c) 2019 S. Karger AG, Basel

E-Mail karger@karger.com

www.karger.com/ear quences are. Results: Two hundred and eighty-eight (2.22\%) patients received anticraving medication, $98(0.76 \%)$ in the first 6 months after inpatient treatment. Fifty-nine of the 288 patients were monitored with a pre- and postcomparison over a 90-day period. Inpatient treatment fell from 0.83 times $( \pm 1.10)$ during the 3 months afterward to $0.79( \pm 1.01)$. On average, the duration of an inpatient stay before anticraving treatment $(n=29)$ was 17.34 days $( \pm 14.37)$, with an average cost of EUR $4,142.70( \pm 2,721.28)$. Among the anticraving treatment group, this fell to 14.03 days $( \pm 9.96)$ with an average cost of EUR 3,685.43 ( $\pm 2,307.67)$. Overall, the average outpatient and inpatient treatment costs dropped from EUR $1,533.88$ before treatment to EUR $1,462.76$ after treatment. If this is extrapolated to the whole group, it leads to between EUR 921,500 and EUR 6.6 million saving for a health insurance company. Conclusion: Anticraving medications are hardly ever prescribed. Their routine use could reduce hospital readmission rates and save on health-care costs.

(c) 2019 S. Karger AG, Basel

\section{Introduction}

Alcoholics are often seen in health-care settings but rarely receive specific treatment [1]. This applies to both outpatient and inpatient care. Studies show that alcohol- 
ics have received some kind of unspecific help for up to 10 years before an effective treatment has been found for their addiction [3]. More than $75 \%$ of those affected will see their family doctor every year and be treated for acute problems. However, the underlying illness is not taken into account [4], with the result that morbidity and mortality are increased [2]. In Germany, about a quarter of alcoholics are treated as inpatients once a year, often for other conditions, but only about $1 \%$ of addicts are given specific treatment in specialist addiction clinics or specialist departments during the same time frame [5].

Often, with alcohol addiction, an individual will aim to permanently abstain from drinking, even though there has been a greater interest in "controlled drinking" approach in recent years.

To be able to abstain, a combination of psychological and pharmacological treatment is recommended $[6,7]$. Anticraving drugs are among the most effective medications that can help patients with alcohol dependence [8]. Their aim is to prevent a relapse back to drinking alcohol without the medication actually having the risk for dependency themselves or having any kind of psychotropic effect [9].

Traditionally, the German addiction treatment system runs parallel to medical treatment structures, with addiction counseling, and withdrawal treatment taking place in addiction centres. The use of pharmaceutical agents was not common place. The $\mu$-opiate receptor antagonist naltrexone, approved in Germany since 2010, and the NMDA receptor antagonist acamprosate, approved in Germany since 1996, can be prescribed as pharmacological therapy of alcohol addiction [10]. Anticraving drugs double the rate of abstinence compared to a placebo and they also increase the retention rate for alcoholics in outpatient treatment [11].

Cochrane's analyses on the effectiveness of anticraving drugs are particularly comprehensive and revealing. Rosner et al. $[12,13]$ have published 2 systematic reviews. Meta-analyses included a total of 24 RCTs with 6,915 patients on acamprosate and 50 RCTs with 7,793 patients on naltrexone. As the results of the 2 Cochrane reviews show, acamprosate reduces the relative risk (RR) of failing to abstain following withdrawal treatment to $86 \%$ of the risk of the control groups treated with a placebo and with psychosocial therapy (RR $0.86,95 \%$ CI $0.81-0,91$ ). Naltrexone reduces the risk of excessive alcohol consumption to $83 \%$ of risk of the control group (RR 0.83 , $95 \%$ CI $0.76-0.90)$. In addition, only a few people experienced significant side effects compared to the placebo group in the trials. Diarrhea was a more common side effect for patients on acamprosate than those taking a pla- cebo (risk difference [RD] 0.11, 95\% CI 0.09-0.13), naltrexone was associated with nausea (RD $0.10,95 \%$ CI $0.07-0.13$ ), daytime fatigue (RD $0.09,95 \%$ CI $0.05-0.14$ ), and loss of appetite (RD 0.07, 95\% CI 0.03-0.11).

Miller et al. [14] gave another review of the current meta-analysis and included 85 studies with 18,937 patients. These studies look at the efficacy of naltrexone, acamprosate, disulfiram, and topiramate. The meta-analysis found that there was a modest effect in relation to prolonged abstinence in naltrexone-treated patients $(6 \%$ prolonged abstinence rate compared to placebo). Acamprosate demonstrates moderate psychopharmacological support to patients who are already abstaining.

In this context, the German S3 guidelines [15] state that in postacute care of patients with alcohol dependence, acamprosate or naltrexone should be offered as part of a comprehensive plan for outpatient treatment.

The effectiveness of anticraving medication must be offset by the infrequent level of their prescription. The Drug Disposition Report 2016 states that Campral ${ }^{\circledR}$ (acamprosate) was prescribed around 16,000 times in 2015 in Germany. The drug registered an 11.8\% decline in prescription compared to the previous year. Overall, Campral ${ }^{\circledR}$ was ranked in 2,935 th position in the 2015 prescriptions for leading 3,000 medicines [16]. Nemexin ${ }^{\circledR}$ (naltrexone) is not present in the 3,000 leading pharmaceutical prescriptions. A recent U.S. review the US found that both naltrexone and acamprosate are moderately effective and extremely underprescribed [17]. In Germany, only $5 \%$ of appropriate patients are treated. So, opportunities for therapy appear to be underutilized [18].

Since anticraving drugs are often regarded as a "last resort" when the illness is progressing badly, it is more meaningful to make a pre- and postcomparison.

\section{Methods}

Using data of a statutory health insurance company (AOK NordWest, doing business in the Westphalia, Lippe and SchleswigHolstein regions and insuring approximately 2.78 million people), anonymous patients who had undergone inpatient treatment were investigated.

The following inclusion criteria were used:

- A discharge diagnosis of alcohol dependence and/or alcohol withdrawal (as a main or secondary diagnosis, F10.2-F10.4)

- Index inpatient treatment from July 1, 2012, to June 30, 2013 (no selection criteria based on specialist departments)

- Aged 18 years and over

- Insured with the AOK NordWest during the period from July 1,2012 , to December 31, 2013, or had died between July 1, 2012, and December 31, 2013, while with the AOK NordWest. 
Exclusion criterion: Further diagnoses of addiction not counting nicotine addiction.

The data allow tracking the further course of patients regarding treatment with anticraving drugs (acamprosate, naltrexone), rate of readmission to hospital, sick leave, and the costs of the drug over a 6-month period after discharge. In addition, a comparison between patients who were treated with anticraving medication with those who were not treated with them. A cost comparison can be made for medication costs, the costs for inpatient treatment as well as days of illness or days with paid sick leave.

Twelve thousand, nine hundred and fifty-eight individuals with alcohol dependence were identified in the population of the health insurance according to the above named criteria. Of these, 10,088 were male and 2,870 were female, with an average age of 51.4 years $( \pm 12.7)$. The age range was from 18 to 94 years.

Fifty nine patients were identified with an observation period of 90 days before and after their first prescription (April 1, 2013 September 30, 2013).

\section{Results}

\section{Index Treatment Hospitals}

About $49.9 \%(n=6,466)$ of patients were discharged from index treatment with a primary diagnosis of F10.2 or F10.4, and $51.1 \%(n=6,492)$ of patients had a secondary diagnosis. Of the 5,740 patients undergoing index treatment in a mental health institution, 79.2\% $(n=$ $4,544)$ had a F10 main diagnosis and $20.8 \%(n=1,196)$ had a secondary F10 diagnosis when they were discharged.

Treatment costs for the index treatment for those with F10 as the main diagnosis were EUR 2,191.26 $( \pm 1,763.92)$ and EUR 5,236.63 $( \pm 8,920.94)$ for those with a secondary alcohol addiction diagnosis. In total, $44.3 \%(n=5,740)$ of index treatments took place in a psychiatry department at a cost of (EUR 3,008.45 [ $\pm 2,998.19]), 9.2 \%(n=1,196)$ in a surgery department at a cost of (EUR 7,695, 83\% $[ \pm 12,781.94])$ and $4.4 \%(n=566)$ in a neurology department at a cost of (EUR 3,502.91 [ $\pm 5,797.06])$. Totally, $5,456(42.1 \%)$ were treated in another department at a cost of (EUR 3,616.91 [ $\pm 7,159.77])$.

Overall, 6.2\% $(n=861)$ of the patient population died during their index treatment or half a year afterward. Of these, $31.1 \%(n=268)$ died during index treatment and $593(68.1 \%)$ died after an average of 74.4 days $( \pm 53.3)$ following index treatment.

In total, $55.5 \%(n=7,194)$ of the patients were readmitted to hospital after index treatment during a 6-month follow-up, on average 2.3 times. The average length of stay in follow-up was 21.1 days $( \pm 23.5)$ at an average cost of EUR 6,650.47 ( $\pm 10,010.53)$ per patient. Overall, $38.6 \%$ cases were readmitted to inpatient treatment $(n=2.776)$ in departments of psychiatry, $12.3 \%(n=885)$ of surgery, and $3.4 \%(n=245)$ of neurology. Three thousand, two hundred and eighty-eight (45.7\%) were in other departments.

During the 6 months that followed, $93.7 \%(n=12,145)$ of patients were medically treated as outpatients. The average cost per patient was EUR $267.18( \pm 652.63)$. Of these, $81.9 \%$ ( $n=9,951,76.8 \%$ of the total group) of patients were given a prescription for drugs - an average of 7.0 prescriptions ( \pm 6.8 ). The average cost was EUR 545.63 $( \pm 1,316.78)$ for the medication.

Half a year after index treatment, $0.14 \%(n=18)$ patients were prescribed at least once naltrexone and $0.66 \%$ $(n=80)$ acamprosate. For patients in the psychiatry department with F10 as their main diagnosis, $0.09 \%(n=12)$ were treated with naltrexone and $0.38 \%(n=50)$ with acamprosate. Naltrexone was prescribed 2.3 times on average $( \pm 1.9)$ and acamprosate 2.4 times $( \pm 2.2)$. Prescriptions averaged 167 tablets $( \pm 264)$ and $260( \pm 264)$, respectively.

Twenty-seven patients were prescribed the drug for less than a month and 31 patients had a prescription for 1 month. Seventeen patients had prescriptions for anticraving drugs for up to 2 months and 7 for up to 3 months. Only 16 patients had a prescription for 3 months or more. $41.2 \%(n=7)$ of naltrexone prescriptions were handed out by general practitioners, and $55 \%(n=44)$ of acamprosate prescriptions. Neurologists handed out $11.8 \%$ $(n=2)$ of prescriptions for naltrexone and $15 \%$ for acamprosate $(n=12)$.

Those who were prescribed naltrexone were 45.2 years of age on average ( \pm 9.1$)$. The average age of the acamprosate group was $46.3( \pm 10.6)$. The average age of those in the sample group who did not receive an anticraving prescription was $51.5( \pm 12.8)$.

Overall, $37.1 \%(n=36)$ of those treated with anticraving medications started these within a week following index treatment and 52.6\% $(n=52)$ started after 1 month. After 2 months, only $65 \%(n=67)$ were treated. In other words: in the case of the majority of those who received treatment, there was no direct correlation between index treatment and start of treatment with anticraving medications.

When naltrexone was administered, the average total cost of treatment (the total costs for medication plus inpatient and outpatient treatment) was EUR 6,263.24 $( \pm 7,323.24)$ per patient. When acamprosate was administered, it was EUR 5,054.01 ( $\pm 4,699.64)$. The total cost for the patient group without an anticraving prescription came to EUR 4,421.86 $( \pm 8,540.75)$. For those patients 
Table 1. Pre and postcomparison of hospital treatment costs

\begin{tabular}{lll}
\hline \multicolumn{2}{c}{ Pre } & Post \\
\hline Number & $\begin{array}{l}0.83(1.10) \\
\text { 30 patients without prehospitalization }\end{array}$ & $\begin{array}{l}0.79( \pm 1.01) \\
29 \text { patients without posthospitalization }\end{array}$ \\
\hline Duration & $\begin{array}{l}8.5 \text { days }( \pm 13.3) \\
\text { with hospitalization } 17.34 \text { days }( \pm 14.37 ; n=29)\end{array}$ & $\begin{array}{l}7.1 \text { days }( \pm 10.0) \\
\text { with hospitalization } 14.03 \text { days }( \pm 9.96 ; n=30)\end{array}$ \\
\hline Costs & EUR 2,036.24 $\pm 2,817.48$ & EUR $1,873.95 \pm 2,473.02$ \\
& with hospitalization EUR $4,142( \pm 2,721 ; n=29)$ & with hospitalization EUR $3,685( \pm 2,307 ; n=30)$ \\
\hline \multirow{2}{*}{ No significant differences. } & \\
\hline
\end{tabular}

who began anticraving treatment within 1 week of index treatment, the total cost averaged EUR 4,700.16 $( \pm 5,780.50)$ per patient.

To make a pre- and posttreatment comparison, patients $(n=59)$ were evaluated over a 90 -day period before and after their first prescription of an anticraving regimen (April 1, 2013 - September 30, 2013).

Table 1 shows the costs for hospital treatment.

Only 32 people incurred outpatient drug costs in the prephase - an average of EUR $80.80( \pm 121.13)$, followed by an average of EUR $377.89( \pm 323.58)$ in all 59 patients. Medical treatment costs $(n=58)$ reduced slightly from EUR $391.70( \pm 48.97)$ to 354.80 (380.40).

In addition to the personal benefit of fewer days spent in hospital, there are also economic benefits for society. In a model calculation, the total calculated costs (EUR $1,533.88$ pre vs. $1,462.76$ post) are extrapolated to the total group $(n=12,958)$. Assuming that a $30 \%$ abstinence rate for patients with anticraving treatment $(30 \%$ would continuously abstain without treatment, $40 \%$ would relapse despite anticraving medication). This would result in a saving for the health insurance company of 6.6 million Euros in 6 months. Even with a lower rate of $10 \%$ of people benefitting from the treatment, there would be a saving of around EUR 921,500. The costs of sick pay are not taken into account (insufficient number of cases).

\section{Discussion}

Although the clients insured by AOK NordWest represent only a part of the German population, the large number of 12,958 cases and the mix of urban and rural areas in the AOK NordWest area, these clients are likely to be an approximate reflection of persons in a statutory health insurance in Germany. This is also shown by, for example, comparing the treatment distribution in psychiatry or somatic clinics to data from Melchinger et al. [19]. They found that $42.3 \%$ of patients in psychiatric hospitals and $57.7 \%$ in somatic hospitals were treated in psychiatric wards or somatic hospitals.

The mortality rate of $6.2 \%(n=861)$ in the sample that was analyzed is strikingly high, compared to Federal Statistical Office figures [20]: 14,095 deaths in 2014 of German adults with an alcohol-related illness. Although no statement can be made as to whether causes of death in the study population were due to alcohol, taking into account the characteristics from the sample group (diagnosis F10.2), it is highly likely that there was at least an indirect causal relationship between alcohol dependence and mortality. In addition to the high mortality, the rehospitalization rate and the treatment costs show that the efficient treatment of alcohol dependence has a high societal significance. The suffering from complications and loss of social participation cannot be expressed in numbers. It therefore requires increased efforts to offer all effective treatments to patients.

The study does not provide an answer as to why the prescription rate of anticraving medications is so low, although their effectiveness is proven and the numbers needed for treatment are more favorable than, for example, frequently prescribed cholesterol-lowering drugs. An internal (unpublished) study showed that if patients are given intensive education about their withdrawal, it is possible to achieve a success rate of $25 \%$ of all patients.

The number of patients in the pre/postevaluation is small. In this respect, the economic benefit, calculated to the great number of insured persons, has to be seen as a sign for the great chance of treatment with anticraving medications. 


\section{Conclusion}

Although studies show that anticraving drugs can double abstinence rates, they are rarely used and usually as a last resort in severe cases of illness progression. It is striking that there is no strong debate in the professional community about anticraving medication, unlike the argument 25 years ago between biologically oriented psychiatrists, and more psychotherapeutic oriented psychiatrists and psychotherapists about the drug treatment of depression. There needs to be further research to under- stand why therapists and sufferers do use drug treatment approaches only in rare cases of addiction treatment.

Positive Ethics vote from the Ethics Commission of the Medical Association Westfalen-Lippe and the Faculty of Medicine of the University of Westphalia Wilhelms University of November 20, 2013 (2013-038-f-S).

\section{Disclosure Statement}

The authors have no conflicts of interest to declare.

\section{References}

1 Rehm J, Rehm M, Shield KD, Gmel G, Frick U, Mann K. Reduzierung alkoholbedingter Mortalität durch Behandlung der Alkoholabhängigkeit. Sucht. 2014;60(2):93-105.

2 Kraus L, Pabst A, Piontek D, Müller S. Trends des Substanzkonsums und substanzbezogener Störungen. Sucht. 2010;56(5): 337-47.

3 Driessen M, Veltrup C, Junghanns K, Przywara A, Dilling H. Kosten-Nutzen-Analyse klinisch-evaluierter Behandlungsprogramme. Der Nervenarzt. 1999;70(5):46370.

4 John U, Hapke U, Rumpf HJ, Meyer C, Bischof G. Suchtkranke in der somatischen Medizin. Suchttherapie. 2001;2:15-9.

5 Wienberg G, editor. Die vergessene Mehrheit. Zur Realität der Versorgung alkohol- und medikamentenabhängiger Menschen. Berlin: Psychiatrie-Verlag; 1992. pp. 12-60.

6 Smolka MN, Kiefer F, Mann K. Fortschritte in der Behandlung von Alkoholabhängigen: die medikamentöse Rückfallprophylaxe. MMW. 2003;3:65-9.

7 Mann K, Hermann D. Individualised treatment in alcohol-dependent patients. Eur Arch Psychiatry Clin Neurosci. 2010 Nov; 260(Suppl 2):S116-20.

8 Spanagel R, Vengeliene V. New pharmacological treatment strategies for relapse prevention. Curr Top Behav Neurosci. 2013;13: 583-609.
9 Mann K, Loeber S, Croissant B, Kiefer F. Qualifizierte Entzugsbehandlung von Alkoholabhängigen. Ein Manual zur Pharmakound Psychotherapie. Köln: Deutscher ÄrzteVerlag; 2006.

10 Lohse MJ, Müller-Oerlinghausen B. Psychopharmaka. In: Schwabe U, Paffrath D, editors. Arzneiverordnungs-Report 2016. Aktuelle Daten, Kosten, Trends und Kommentare. Berlin, Heidelberg: Springer-Verlag; 2016. pp. 663-90.

11 Sass H, Soyka M, Mann K, Zieglgänsberger W. Relapse prevention by acamprosate. Results from a placebo-controlled study on alcohol dependence. Arch Gen Psychiatry. 1996 Aug;53(8):673-80.

12 Rösner S, Hackl-Herrwerth A, Leucht S, Lehert P, Vecchi S, Soyka M. Acamprosate for alcohol dependence. Cochrane Database Syst Rev. 2010 Sep;9(9):CD004332.

13 Rösner S, Hackl-Herrwerth A, Leucht S, Vecchi S, Srisurapanont M, Soyka M. Opioid antagonists for alcohol dependence. Cochrane Database Syst Rev. 2010 Dec;12(12): CD001867.

14 Miller PM, Book SW, Stewart SH. Medical treatment of alcohol dependence: a systematic review. Int J Psychiatry Med. 2011;42(3): 227-66.
15 Mann K, Batra A, Hoch E und die Leitliniengruppe. S3-Leitlinie "Screening, Diagnose und Behandlung alkoholbezogener Störungen". Sucht. 2017;63(1):7-23.

16 Schaufler J, Telschow C, Weiss J. Ergänzende statistische Übersicht. In: Schwabe U, Paffrath D, editors. Arzneiverordnungs-Report 2016. Aktuelle Daten, Kosten, Trends und Kommentare. Berlin, Heidelberg: SpringerVerlag; 2016. pp. 785-821.

17 Friedmann PD. Alcohol use in adults. N Engl J Med. 2013 Apr;368(17):1655-6.

18 Fritze J. Psychopharmaka-Verordnungen: Ergebnisse und Kommentare zum Arzneiverordnungsreport 2013. Psychopharmakotherapie. 2014;21:153-66.

19 Melchinger H, Machleidt W, Rössler W. Ausgaben auf den Prüfstand. Dtsch Arztebl. 2003; 100:B-2370.

20 Statistisches Bundesamt. Sterbefälle, Sterbeziffern (je 100.000 Einwohner, alterststandardisiert) ab 1998. Gliederungsmerkmale: Jahre, Region, Alter, Geschlecht, Nationalität, ICD-10, Art der Standardisierung. Available from: http://www.gbe-bund.de/oowa921-install/servlet/oowa/aw92/WS0100/_XWD_ FORMPROC? TARGET $=\&$ PA GE $=$ XWD_112\&OPI.NDEX $=1 \&$ HANDLER $=$ XWD_CUBE.SETPGS\&DATACUBE $=$ XW D_140\&D. $000=3737 \& D .0 .01=1000001 \& D .0$ $02=1000002 \& D .003=1000004 \& D .004=44$ $\& D .011=44302$ (Accessed online: 30.06.2018). 